\title{
LETTERS
}

\section{Mercury poisoning in the Grassy Narrows First Nation: history not completed}

The article published in CMAJ by Mosa and Duffin outlines the history of mercury poisoning of the Grassy Narrows First Nation along the English-Wabigoon River. ${ }^{1}$ The Grassy Narrows First Nation is located about $100 \mathrm{~km}$ downstream from the Dryden Chemical Company. This company dumped tonnes of mercury into the river between 1962 and 1970, some 50 years ago. The authors link this history with that of mercury poisoning in Minamata, Japan, in the 1950s. ${ }^{1}$

Mercury levels downstream of the plant should have returned to normal by now in the absence of leaks. However, a recent study, authored by five mercury experts and released on Feb. 28, 2017, reported that tests showed significantly higher mercury levels downstream of the plant compared with upstream locations roughly 130 times higher. The report suggests that the area is being subjected to ongoing pollution rather than the aftermath of chemical release that occurred in the 1960s. ${ }^{2}$

The Ontario provincial government and the federal government should urgently eliminate the ongoing problem. Otherwise, the mercury poisoning will continue to affect the health, economy and culture of the Grassy Narrows First Nation for another 50 years, if not more.

\section{H.C. George Wong MD}

Clinical Professor, Division of Allergy and Immunology, Department of Medicine, The University of British Columbia, Vancouver, BC

Cite as: CMAJ 2017 June 5;189:E784. doi: 10.1503/cmaj.733011

\section{References}

1. Mosa A, Duffin J. The interwoven history of mercury poisoning in Ontario and Japan. CMAJ 2017;189: E213-5.

2. Loriggio P. Study claims mercury still leaking from mill near Grassy Narrows: chief. Globe and Mail [Toronto]. Available: www.globeandmail .com/news/national/study-claims-mercury-still -leaking-from-mill-near-grassy-narrows-chief/ article34160163/ (accessed 2017 Apr. 11).

Competing interests: None declared. 